\title{
USAHA PENANGKAPAN BENIH SIDAT MENGGUNAKAN ALAT TANGKAP SESER DI MUARA CIBUNI-TEGAL BULEUD-SUKABUMI JAWA BARAT
}

\author{
Capture Business of Glass Eel Capture Fishery with Scope Net Gear in Cibuni River Mouth-Tegal \\ Buleud -Sukabumi - West Java Province
}

Oleh:

\author{
Mohammad Imron ${ }^{1}$,Rizqi Ramadhan Putra ${ }^{2}$, Mulyono S Baskoro ${ }^{1}$, Deni Achmad \\ Soeboer ${ }^{3}$ \\ ${ }^{1}$ Pengajar Departemen PSP-FPIK-IPB \\ ${ }^{2}$ PT Perikanan Indonesia \\ ${ }^{3}$ Pascasarjana TPL-Dep PSP-FPIK-IPB \\ *Korespondensi: mohammad.imron@gmail.com
}

\begin{abstract}
ABSTRAK
Usaha penangkapan benih sidat merupakan kegiatan utama dalam memenuhi kebutuhan akan benih sidat untuk kegiatan pembesaran, itu dikarenakan belum ditemukannya cara untuk memproduksi benih secara buatan. Benih sidat hanya dihasilkan dari alam melalui usaha penangkapan. Penangkapan benih sidat dipengaruhi oleh faktor lingkungan, salah satu faktor lingkungan yang dilihat yaitu kondisi fase bulan, dimana fase bulan ini berpengaruh pada sifat alami benih sidat yang menghindari predator. Daerah penangkapan benih sidat adalah muara sungai Cibuni, Tegal buleud, Sukabumi. Muara sungai Cibuni berada di selatan Pulau Jawa yang memiliki potensi besar dalam penyediaan benih sidat, namun belum ada penelitian yang dilakukan seperti dimuara sungai Cimandiri, Pelabuhanratu. Produktifitas hasil tangkapan dalam penelitian ini hanya dipengaruhi waktu. Produktifitas juga berpengaruh kepada penghasilan yang didapatkan oleh nelayan, oleh karena itu penelitian ini bertujuan untuk mengetahui kelayakan usaha, metode, waktu yang tepat, dan konstruksi alat penangkapan benih sidat di muara sungai Cibuni, Tegal buleud, Sukabumi, Jawa barat. Data yang dikumpulkan dalam penelitian ini berupa data primer dan sekunder. Data primer secara khusus dikumpulkan dengan mengamati aspek teknologi dan aspek ekonomi. Dari hasil analisis menunjukan alat tangkap seser masuk dalam klasifikasi alat tangkap lift nets. Usaha penangkapan benih sidat masih layak dilakukan, dengan nilai Revenue cost ratio ( $R / C$ ratio) sebesar 2.75 , Return of investment (ROI) sebesar 75,24\%, dan Payback period $(P P)$ sebesar 0.16 tahun, dan waktu yang tepat dalam penangkapan dilakukan saat gelap bulan.
\end{abstract}

Kata kunci: benih sidat, usaha penangkapan, fase bulan, Tegal Buleud

\begin{abstract}
The main activity of Glass eel capture business is for supply eel aquaculture activities, the glass eel are only produced from nature. Catching glass eel is influenced by environmental factors, one of the environmental factors seen is the condition of the moon phase, where the moon's phase influencesthe nature of glass eel which avoids predators. The area of catching glass eel is the estuary of Cibuni, Tegal Buleud, Sukabumi. Cibuni estuary is in the south of Java Island which has great potential in the supply of glass eel, but no research has been carried out such as in the Cimandiri river, Pelabuhanratu. The productivity of the catch in this study is only influenced by time. Productivity also affects the income earned by fishermen, therefore this study aims to determine the business feasibility, methods, timing, and construction of fishing equipment for eel seedlings in the estuary of the Cibuni
\end{abstract}


River, Portugal, Sukabumi, West Java. The data collected in this study are primary and secondary data. Primary data is specifically collected by observing technological aspects and economic aspects. From the results of the analysis, the sealing device is included in the classification of elevator nets. Efforts to catch eel seeds are still feasible, with Revenue cost ratio ( $R$ / C ratio) of 2.75, Return of investment (ROI) of $75.24 \%$, and Payback period (PP) of 0.16 years, and the right time of arrest done when the moon is dark.

Key words: Glass eel, fishing effort, moon phase, Tegal Buleud

\section{PENDAHULUAN}

Ikan sidat memiliki nilai ekonomis tinggi dan permintaan global yang semakin meningkat (CITES, 2007). Faktor yang menyebabkan ikan ini bernilai ekonomis tinggi dan menjadi komoditas ekspor diantarana karena kandungan gizi ikan sidat yang tinggi, dagingnya yang lembut juga dapat menyembuhkan penyakit kulit, dan pertambahan penduduk dunia juga meningkatkan kebutuhan akan sumber protein makanan daging dan ikan.

Tegal Buleud, Sukabumi merupakan salah satu wilayah yang memiliki muara sungai yang menjadi jalur ruaya benih ikan sidat. Sukabumi merupakan kabupaten yang berada di Jawa barat dan memiliki garis pantai dengan beberapa muara sungai salah satunya muara sungai Cibuni. Berdasarkan habitatnya, benih ikan sidat tumbuh di perairan tawar (sungai dan danau) hingga mencapai dewasa setelah itu ikan sidat dewasa beruaya ke laut untuk melakukan reproduksi, dengan sifat benih ikan sidat yang katadromus (beruaya dari salinitas yang tinggi menuju salinitas yang rendah) maka dapat diindikasikan terdapat benih sidat yang beruaya melalui muara tersebut. Kondisi fase bulan gelap dan terang juga berpengaruh dalam usaha pengakapan benih sidat dimana benih ikan sidat ini memiliki naluri untuk menghindari predator saat beruaya.

Benih ikan sidat dihasilkan melalui penangkapan di muara sungai. Alat tangkap yang biasa di gunakan oleh nelayan salah satunya menggunakan seser, banyak bermacam-macam bentuk dari seser karena banyak nelayan yang telah melakukan modifikasi alat tangkap yang bertujuan untuk lebih menguntungkan usaha penangkapan.

Benih hasil alam inilah yang menjadi kendala bagi setiap perusahaan yang ingin mengembangkan usaha pembesaran ikan sidat di Indonesia. Untuk mendorong pengembangan usaha pembesaran ikan sidat di dalam negeri dan pemenuhan kebutuhan akan benih sidat bagi perusahaan yang telah menginvestasikan modal usahanya di Indonesia, maka mendorong pemerintah mengeluarkan peraturan tentang pelarangan ekspor benih sidat dari wilayah Indonesia keluar wilayah Indonesia, dalam Peraturan Menteri Kelautan dan Perikanan Republik Indonesia Nomor Per.18/men/2009, (Kementrian Kelautan dan Perikanan, 2009). Berdasarkan hal tersebut maka perlu adanya penelitian mengenai usaha penangkapan benih sidat dengan alat tangkap seser di muara Cibuni Tegal Buleud Sukabumi Jawa barat, untuk meneliti lebih lanjut mengenai alat tangkap seser yang digunakan agar mempermudah nelayan dalam penangkapan dan dapat memenuhi kebutuhan benih sidat dalam negeri. Penangkapan benih ikan sidat merupakan salah satu kendala yang dihadapi nelayan, karena hasil tangkapan yang semakin berkurang. Dalam mendukung usaha kegiatan penangkapan benih sidat di muara sungai Cibuni, Tegal Buleud, Sukabumi maka perlu adanya suatu teknik dan alat untuk mempermudah nelayan dalam menangkap benih sidat, karena belum ditemukan cara pengembangbiakan secara buatan. Sifat alami benih sidat yang beruaya dari salinitas tinggi menuju salinitas rendah (katadromus) dan menghidar dari prodator juga mempengaruhi hasil tangkapan. Tujuan penelitian ini adalah mengetahui produktifitas alat tangkap seser, ditinjau dalam aspek teknologi dengan mendeskripsikan alat dan aktivitas penangkapan benih sidat, mengetahui kelayakan usaha dalam pengankapan benih sidat berdasarkan hasil tangkapan, mengetahui waktu yang tepat dalam penangkapan benih sidat dilihat dari perbedaan fase bulan. 


\section{METODOLOGI PENELITIAN}

Penelitian ini akan dilaksanakan selama enam bulan dan dimulai pada bulan April 2016 sampai bulan Oktober 2016 di muara Cibuni Tegal buleud, Sukabumi, Jawa barat. Metode pengambilan data penelitian ini merupakan pengamatan kegiatan penangkapan (observasi). Data diperoleh dengan mengamati operasi penangkapan ikan di muara sungai mengunakan seser. Data penelitian ini diolah dengan membandingkan hasil tangkapan berdasarkan dua perlakuan waktu yang berbeda menggunakan uji anova dengan batas perlakuan perbedaan waktu (fase bulan gelap dan bulan terang). Data yang dikumpulkan dalam penelitian ini berupa data primer dan sekunder. Data primer adalah sumber data yang diperoleh secara langsung dari sumber asli atau pihak pertama. Data primer secara khusus dikumpulkan dengan mengamati.

\section{Aspek Tekonologi}

Berhubungan dengan metode operasi penangkapan, deskripsi alat tangkap dan daerah penangkapan, meliputi: metode pengoperasian alat tangkap, ukuran alat tangkap dan jumlahnya, konstruksi dan bagian-bagian alat tangkap, daerah pengoperasian, jumlah nelayan pengoperasian alat tangkap seser, jumlah trip, musim penangkapan, dan banyaknya waktu yang dibutuhkan untuk pengoperasian alat tangkap.

\section{Aspek Ekonomi}

Data yang berhubungan dengan analisis biaya usaha, meliputi: pendapatan nelayan dalam satu periode waktu (hari/minggu/bulan/tahun), biaya operasional yang dikeluarkan, biaya investasi yang dikeluarkan untuk memulai usaha penangkapan, produksi alat penangkapan, harga jual hasil tangkapan, daerah pemasaran hasil tangkapan dan keuntungan yang diperoleh dari hasil penjualan hasil tangkapan.

\section{Analisis Data}

\section{Analisis Kegiatan Operasi Penangkapan Ikan}

Kegiatan operasional penangkapan ikan menggunakan metode deskriptif. Metode deskriptif adalah mendeskripsikan atau menggambarkan data dan informasi yang diperoleh selama penelitian. Analisis dilakukan dengan menjelaskan kegiatan operasi penangkapan sidat dari persiapan, penentuan daerah penangkapan ikan, proses penangkapan, pengangkutan dan pengelolaan hasil tangkapan (Selvina et al. 1993 dalam Putra, 2015). Hasil analisis tersebut dapat disajikan dalam bentuk tabel, grafik atau gambar yang relevan. Metode deskriptif pada penelitian ini bertujuan untuk menggambarkan aktivitas penangkapan benih sidat menggunakan alat tangkap seser di muara sungai Cibuni Tegal Buleud, Sukabumi, Jawa barat.

\section{Analisis Aspek Teknologi}

Analisis data untuk aspek teknologi meliputi analisis deskriptif dan perhitungan produktivitas dari unit penangkapan benih sidat menggunakan seser di muara sungai Cibuni. Faktor teknologi yang ada dalam tiap unit penangkapan seser diantaranya, yaitu desain kontruksi, metode pengoperasian dan produktivitas unit penangkapan seser.

Desain kontruksi dan Metode pengoperasian, Analisis dengan metode deskriptif dan disajikan dalam bentuk desain gambar dari alat tangkap seser. Kemudian dibandingkan dengan pustaka lain. Analisi dengan metode deskriptif mengenai teknik pengoperasian, waktu pengoperasian, tujuan penangkapan dan alat bantu yag digunakan.

\section{Analisis Aspek Ekonomi}

Analisis aspek ekonomi merupakan rencana investasi melalui perhitungan biaya dan manfaat yang diharapkan, dengan membandingkan antara pengeluaran dan pendapatan. Analisis aspek ekonomi bertujuan untuk menentukan rencana investasi melalui perhitungan biaya dan manfaat yang 
diharapkan, dengan membandingkan antara pengeluaran dan pendapatan, seperti ketersediaan dana, biaya modal, kemampuan proyek untuk membayar kembali dana tersebut dalam waktu yang telah ditentukan dan menilai apakah proyek akan dapat berkembang terus. Analisis ini melihat keunggulan dan kelayakan pengembangan dari alat tangkap seser melalui pendekatan analisis usaha meliputi analisis usaha merupakan pemeriksaan keuangan untuk mengetahui sampai sejauh mana keberhasilan usaha selama usaha itu berlangsung (Rahardi et al. 1993). Dalam analisis usaha perlu dihitung beberapa tolak ukur profitabilitas seperti analisis laba/rugi, Analisis Payback Period(PP), Return of Invesment (ROI) dan Analisis Revenue Cost Ratio (Kadariah et al. 1999).

Analisis laba/rugi, analisis laba/rugi bertujuan untuk mengetahui besarnya keuntungan dan kerugian dari usaha yang dikelola. Keuntungan = Total penerimaan - (total biaya tetap + total biaya variabel). Kriteria, $\mathrm{TP}>\mathrm{TBT}+\mathrm{TBV}$; berarti usaha untung, $\mathrm{TP}=\mathrm{TBT}+\mathrm{TBV}$; berarti usaha tidak untung dan tidak rugi, $\mathrm{TP}<\mathrm{TBT}+\mathrm{TBV}$; berarti usaha rugi.

Analisis Payback Period (PP) Analisis ini bertujuan untuk mengetahui berapa lama waktu yang diperlukan bagi aliran tunai yang dihasilkan oleh suatu kegiatan investasi untuk menutup semua biaya atau modal awalnya, yang dihitung dengan menggunakan formula:

$$
P P=\frac{\text { InCap }}{\text { AnnualCF }} \times 1 \text { tahun }
$$

Keterangan:

InCap = Modal awal yang dikeluarkan (Investasi);

AnnualCap $\quad=$ Aliran tunai bersih pertahun (Keuntungan);

Analisis Return of Investment (ROI) merupakan nilai yang digunakan untuk mengetaui keuntungan yang diperoleh nelayan dari setiap jumlah uang yang diinvestasikan dalam periode waktu tertentu yang diformulasikan sebagai berikut:

ROI $=($ Keuntungan/Investasi $) \times 100 \%$

\section{Analisis Revenue Cost Ratio (R/C)}

Analisis Revenue Cost Ratio (R/C) merupakan analisis untuk melihat keuntungan relatif suatu usaha dalam satu tahun terhadap biaya yang dipakai dalam kegiatan usaha tersebut. Suatu usaha dikatakan untung apabila nilai $\mathrm{RC}$ rationya lebih besar dari $1(\mathrm{R} / \mathrm{C}>1)$. Hal ini menggambarkan semakin tinggi nilai $\mathrm{R} / \mathrm{C}$ maka keuntungan yang didapat semakin besar.

$\mathrm{R} / \mathrm{C}=($ Total Penerimaan / (total biaya tetap+total biaya variabel) $)$

Kriteria

$\mathrm{R} / \mathrm{C}>1$; Usaha menguntungkan, maka usaha layak untuk dilanjutkan atau dikembangkan

$\mathrm{R} / \mathrm{C}=1$; Usaha tidak untung dan tidak rugi

$\mathrm{R} / \mathrm{C}<1$; Usaha rugi, maka usaha tidak layak untuk dikembangkan.

\section{Analisis penentuan waktu yang efektif dalam penangkapan benih sidat berbasih hasil tangkapan}

Penentuan waktu yang tepat dalam penangkapan benih sidat di muara Cibeni Tegal Buleud, Sukabumi, Jawa barat dilakukan dengan menggunakan analisis deskriptif kuantitatif. Analisis deskriptif kuantitatif menggunakan metode uji anova di mana diasumsikan bahwa data telah tersebar normal dan untuk menentukan nilai Ftab dan Fhit mengunakan aplikasi SPSS. Hipotesis yang digunakan adalah jika Fhit > Ftab, maka tolak H0 yang berarti fase bulan akan memberikan pengaruh nyata terhadap hasil tangkapan glass eel dan sebaliknya apabila Fhit < Ftab maka terima H0, yang artinya fase bulan tidak memberikan pengaruh yang nyata terhadap hasil tangkapan glass eel. 


\section{HASIL DAN PEMBAHASAN}

\section{Unit Penangkapan Seser/Sirib}

Berdasarkan hasil penelitian, unit penangkapan seser/sirib yang terdapat di muara sungai Cibuni terdiri dari alat tangkap, dan nelayan. Berikut ini merupakan deskripsi dari unit penangkapan seser/sirib di muara sungai Cibuni.

\section{Klasifikasi Alat Tangkap Seser/Sirib}

Seser/sirib termasuk dalam klasisifikasi jaring angkat (lift net). Seser/sirib dikhususkan untuk menangkap benih-benih ikan yang berada di pinggiran pantai seperti benih sidat. Alat tangkap seser merupakan alat tangkap jaring angkat yang paling sederhana dan berukuran relative kecil.

\section{Desain Konstruksi}

Alat tangkap seser yang berada di daerah muara sunga Cibuni, Tegal Buleud terbuat dari kain kelambu yang berbentuk persegi ukuran 200x200 cm dengan bingkai tali berdiameter $0.5 \mathrm{~cm}$ yang di sanggah oleh empat bilah kayu masing-masing sepanjang $200 \mathrm{~cm}$, lalu sisi ujung kayu tersebut di satukan di ujung sisi yang tidak terhubung dengan kain kelambu dan diikat untuk lebih jelas dapat dilihat pada Gambar 2.
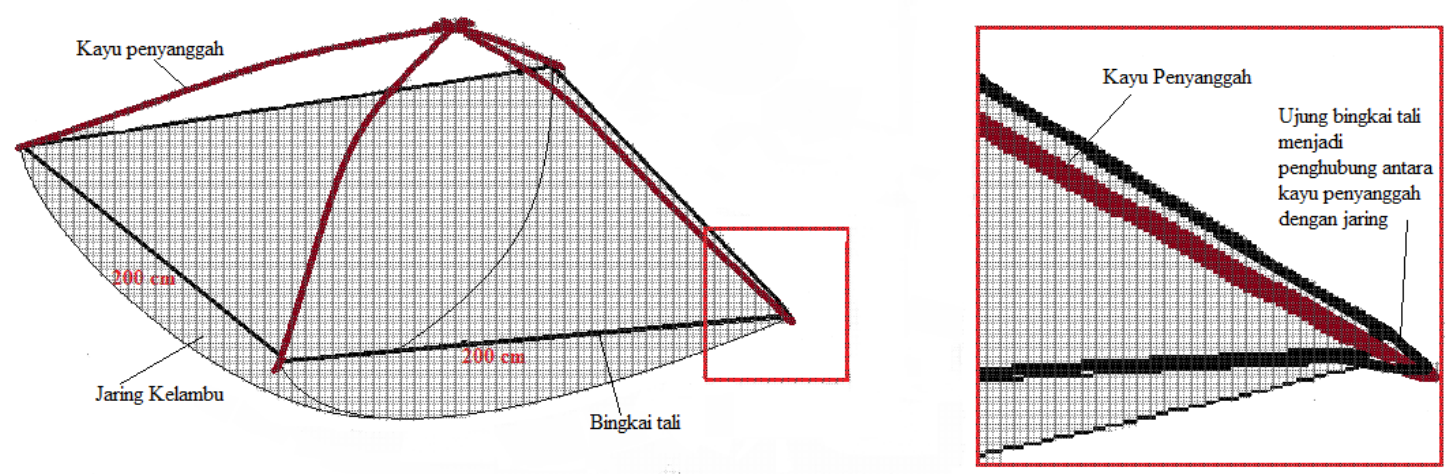

Gambar 2. Desain konstruksi unit penangkapan seser

\section{Metode Pengoprasian alat tangkap}

Pengoprasian alat tangkap seser/sirib di mulai dari tahap persiapan sampai kembali ke penampungan membutuhkan waktu satu hari melaut, yakni dari jam 18.00-06.00 WIB. Pengoperasian seser/sirib yaitu dimulai dari tahap persiapan, tahap menuju daerah penangkapan, tahap pemasangan alat tangkap (setting) dan operasi penangkapan, tahap pengumpulan hasil tangkapan dipenampungan.

\section{Persiapan}

Pada tahap persiapan sebelum berangkat kedaerah penangkapan meliputi persiapan alat tangkap, alat bantu penangkapan dan perbekalan

a. Alat tangkap

Alat tangkap seser/sirib disiapkan, dicek dan dirapihkan sedemikian rupa agar mudah di bawa kepinggir pantai.

b. Alat bantu penangkapan

Alat bantu penangkapan seperti petromak dan senter di siapakan untuk memberikan penerangan dalam penangkapan.

c. Perbekalan

Masing-masing nelayan menyiapkan perbekalan (makanan, air tawar, rokok, dan kopi) untuk dikonsumsi ketika menunggu peralihan waktu antara air surut ke air pasang. 


\section{Menuju daerah penangkapan}

Nelayan bertemu dititik pertemuan yang sudah ditentukan oleh ketua kelompok penangkap pada pukul 19.00 WIB. Lokasi pertemuan berada dipinggir pantai yang berdekatan dengan muara sungai Cibuni.

\section{Setting alat tangkap dan operasi penangkapan}

Seorang nelayan mengoprasikan satu unit alat tangkap seser/sirib ini dengan bantuan petromak sebagai penerangan. Setting alat dilakukan dipinggiran pantai lokasi penangkapan. Setelah alat siap digunakan nelayan menunggu waktu datangnya air pasang. Perkiraan waktu air pasang dimulai dari pukul 20.00-23.00 WIB kemudian surut, lalu pukul 02.00-05.00 WIB air pasang kembali. Ketika ketua kelompok sudah memberi tahu bahwa air sudah mulai pasang, maka para nelayan yang lain memulai penagkapannya. Operasi penangkapan dilakukan dipinggir pantai dengan bantuan petromak. Masing-masing nelayan membawa satu unit alat tangkap seser/sirib. Cara pengoperasian alat tangkap dengan membelakangi ombak yang datang menuju pantai. Ketika ombak datang, seser/sirib diturunkan untuk menghadang benih sidat yang hanyut terbawa ombak. Nelayan mengangkat seser/sirib sebelum ombak mulai berbalik kembali kearah laut dan disaat itu juga dilakukan pengecekan terhadap hasil tangkapan yang terdapat di seser/sirib. Jika ditemukan benih sidat yang tertangkap, nelayan tersebut akan langsung memasukannya kedalam wadah penanpungan sementara.

\section{Pengumpulan hasil tangkapan}

Pengumpulan benih sidat yang didapatkan selama satu malam ditempatkan dipenampungan milik ketua kelompok. Benih yang didapat ditimbang dan diletakan didalam kotak sterofoam yang diberi gelembung udara agar dapat bertahan hidup. Kurang lebih hingga tiga hari/tiga kali trip barulah ketua kelompok ini membagi upah hasil penjulan tangkapan sesuai benih sidat yang masing-masing nelayan dapatkan.

\section{Nelayan}

Nelayan seser/sirib dimuara sungai Cibuni Tegal Buleud merupakan nelayan penuh dimana nelayan tersebut hanya menggantungan hidupnya dengan berprofesi sebagai nelayan. Nelayan dalam penelitian bekerja sama dalam grup yang berjumlah 8 orang yang diketuai oleh bapak Yaya, beliaulah yang memulai usaha dan membuat penampungan benih sidat di daerah tersebut.

Bentuk unit penangkapan seser ini tidak berbeda jauh dengan alat tangkap jaring angkat anco. Jaring angkat anco (Portable lift nets) adalah jaring angkat yang dipasang menetap di perairan, berbentuk empat persegi panjang, terdiri dari jaring yang keempat ujungnya diikat pada dua bambu yang dibelah dan kedua ujungnya dihaluskan (diruncingkan) kemudian dipasang bersilangan satu sama lain dengan sudut 90 derajat. Berdasarkan cara pengoperasiannya, anco tetap diklasifikasikan kedalam kelompok jaring angkat (lift nets) (Subani dan Barus 1989). Alat tangkap jaring angkat anco dapat dilihat pada Gambar 3.

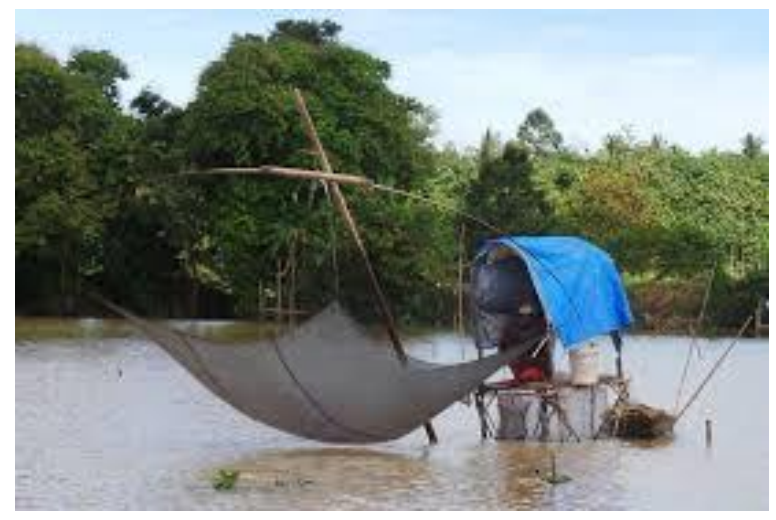

Gambar 3. Jaring angkat anco (sumber: www.google.com) 
Anco atau portable lift nets termasuk alat tangkap yang sangat sederhana, terbuat dari bambu sebagai alat untuk menaik dan menurunkuan jaring, mata jarring anco relative lebih kecil karena tujuan penangkapan ikan adalah ikan-ikan kecil seperti ikan petek, lebar jaring anco sangat bervariasi dari 1 $\mathrm{m}$ dan ada pula yang sampai $5 \mathrm{~m}$. Alat ini bila di oprasikan harus dengan bantuan lampu atau umpan untuk menarik ikan (Subani dan Barus 1989).

\section{Biaya dan Penerimaan Unit Penangkapan Seser/Sirib}

Biaya dan penerimaan merupakan faktor yang dapat melihat apakah suatu usaha itu menguntungkan nelayan atau tidak. Untuk menentukan suatu usaha menguntungkan atau tidak maka perlu dilakukan analisis usaha penangkapan seser/sirib tersebut. Analisis usaha yang dilakukan antara lain:

\section{Biaya}

\section{Investasi Unit Penangkapan Seser}

Investasi merupakan biaya yang dikeluarkan untuk memulai usaha dalam perikanan tangkap. Berdasarkan data yang diperoleh pada saat penelitian, rincian modal investasi yang ditanamkan pemilik usaha unit penangkapan seser/sirib dapat dilihat pada Tabel 1.

Tabel 1. Biaya Investasi unit penangkapan seser

\begin{tabular}{lllr}
\hline Investasi & Jumlah & Umur teknis & Nilai(Rp) \\
\hline Alat tangkap & $4(@ 50.000)$ & 1 tahun & 200.000 \\
Petromak & $1(@ 300.000)$ & 1 tahun & 300.000 \\
Total investasi & & & 500.000 \\
\hline
\end{tabular}

Sumber: Data olahan primer 2016

Biaya modal investasi yang ditanamkan untuk usaha unit seser/sirib sebesar Rp.500.000. Modal investasi tersebut dalam bentuk alat tangkap,dan petromak(alat bantu penangkapan). Modal investasi terbesar adalah untuk membeli petromak sebesar Rp.300.000 dari total investasi. Modal investasi terendah pada usaha unit penangkapan seser/sirib adalah untuk pembelian alat tangkap dari total investasi.

\section{Biaya Oprasional Seser}

Biaya operasional unit penangkapan seser/sirib berupa biaya tetap (fixed cost) dan biaya tidak tetap ( Variabel cost). Biaya tetap adalah biaya yang harus dikeluarkan dalam jumlah yang sama tanpa terpengaruh oleh besar kecilnya kegiatan produksi. Biaya tetap usaha penangkapan seser disajikan pada Tabel 2.

Tabel 2. Biaya tetap oprasional seser selama satu tahun

\begin{tabular}{lclr}
\multicolumn{1}{c}{ Biaya tetap } & Jumlah & keterangan & Nilai (Rp) \\
\hline Perawatan alat tangkap & 4 & @Rp. 25.000 & 100.000 \\
Perawatan petromak & 1 & @Rp. 50.000 & 50.000 \\
Penyusutan alat tangkap & 4 & @Rp. 50.000 & 200.000 \\
Penyusutan petromak & 1 & @Rp. 300.000 & 300.000 \\
Total biaya tetap & & & 650.000
\end{tabular}

Sumber: Data olahan primer 2016

Total biaya tetap usaha penangkapan benih sidat dimuara sungai Cibuni Tegal buleud sebesar Rp.650.000. Biaya terbesar yang dikeluarkan untuk perawatan alat tangkap Rp. 100.000 per tahun. Biaya terkecil yang dikeluarkan untuk perawatan petromak sebesar Rp.50.000 per tahun. Biaya terbesar yang dikeluarkan untuk penyusutan petromak sebesar Rp.300.000 per tahun. Biaya terkecil yang dikeluarkan untuk penyusutan alat tangkap sebesar Rp.200.000 per tahun.

Biaya tidak tetap adalah biaya yang dikeluarkan untuk membiayai kegiatan operasional penangkapan seser/sirib. Biaya tidak tetap pada usaha penangkapan seser/sirib meliputi BBM, dan perbekalan. Biaya tidak tetap usaha penangkapan seser/sirib disajikan pada Tabel 3. 
Tabel 3. Biaya tidak tetap oprasional seserselama satu tahun

\begin{tabular}{lcr}
\hline \multicolumn{1}{c}{ Biaya tidak tetap } & Keterangan & Nilai (Rp) \\
\hline BBM & 3 L x 336 trip x Rp.10.000 & 10.080 .000 \\
Perbekalan & 1 orang x 336 trip x Rp.30.000 & 10.080 .000 \\
Total biaya tidak tetap & & 20.160 .000 \\
\hline
\end{tabular}

Sumber: data primer 2016

Biaya usaha penangkapan benih sidat untuk membeli BBM sebesar Rp. 10.080.000 untuk satu tahun. Biaya untuk persediaan perbekalan sebesar Rp. 10.080.000 untuk satu tahun. Total biaya tidak tetap kegiatan operasional penangkapan benih sidat sebesar Rp. 20.160.000 dan total biaya tetap sebesar Rp. 650.000, jadi total biaya operasional usaha penangkapan benih sidat dimuara Cibuni Tegal buleud sebanyak Rp.21.380.000

\section{Penerimaan usaha penangkapan seser}

Peneriamaan yang diperoleh dari usaha penangkapan benih sidat sepanjang tahun mempunyai rata-rata total hasil tangkapan dan harga jual yang sama. Penerimaan usaha penangkapan benih sidat disajikan pada tabel 4 .

Tabel 4. Penerimaan usaha penangkapan seser selama satu tahun

\begin{tabular}{|c|c|c|c|c|c|c|}
\hline Bulan & $\begin{array}{l}\text { waktu } \\
\text { bulan }\end{array}$ & $\begin{array}{l}\text { Total Hasil } \\
\text { Tangkapan } \\
\text { (Kg) }\end{array}$ & $\begin{array}{l}\text { produktifitas/ } \\
\text { trip/unit/jam } \\
(\mathrm{Kg})\end{array}$ & $\begin{array}{c}\text { Rata-rata Hasil } \\
\text { Tangkapan } \\
\text { /nelayan }(\mathrm{Kg})\end{array}$ & $\begin{array}{l}\text { Harga Ikan } \\
\quad(\mathrm{Rp})\end{array}$ & $\begin{array}{l}\text { Rata-rata } \\
\text { Pendapatan } \\
\text { /Nelayan (Rp) }\end{array}$ \\
\hline \multirow{2}{*}{1} & Terang & 5 & 0.007 & 0.625 & $1,600,000$ & \multirow{2}{*}{$3,720,000$} \\
\hline & Gelap & 13.6 & 0.020 & 1.700 & $1,600,000$ & \\
\hline \multirow{2}{*}{2} & Terang & 6.5 & 0.010 & 0.813 & $1,600,000$ & \multirow{2}{*}{$5,740,000$} \\
\hline & Gelap & 22.2 & 0.033 & 2.775 & $1,600,000$ & \\
\hline \multirow{2}{*}{3} & Terang & 9.8 & 0.015 & 1.225 & $1,600,000$ & \multirow{2}{*}{$5,180,000$} \\
\hline & Gelap & 16.1 & 0.024 & 2.013 & $1,600,000$ & \\
\hline \multirow{2}{*}{4} & Terang & 8.7 & 0.013 & 1.088 & $1,600,000$ & \multirow{2}{*}{$5,280,000$} \\
\hline & Gelap & 17.7 & 0.026 & 2.213 & $1,600,000$ & \\
\hline \multirow{2}{*}{5} & Terang & 8.4 & 0.013 & 1.050 & $1,600,000$ & \multirow{2}{*}{$4,280,000$} \\
\hline & Gelap & 13 & 0.019 & 1.625 & $1,600,000$ & \\
\hline \multirow{2}{*}{6} & Terang & 2.8 & 0.004 & 0.350 & $1,600,000$ & \multirow{2}{*}{$1,360,000$} \\
\hline & Gelap & 4 & 0.006 & 0.500 & $1,600,000$ & \\
\hline \multirow{2}{*}{7} & Terang & 1.8 & 0.003 & 0.255 & $1,600,000$ & \multirow{2}{*}{980,000} \\
\hline & Gelap & 3.1 & 0.005 & 0.388 & $1,600,000$ & \\
\hline \multirow{2}{*}{8} & Terang & 3.2 & 0.005 & 0.400 & $1,600,000$ & \multirow{2}{*}{$2,960,000$} \\
\hline & Gelap & 11.6 & 0.017 & 1.450 & $1,600,000$ & \\
\hline \multirow{2}{*}{9} & Terang & 3.2 & 0.005 & 0.400 & $1,600,000$ & \multirow{2}{*}{$3,120,000$} \\
\hline & Gelap & 12.4 & 0.018 & 1.550 & $1,600,000$ & \\
\hline \multirow{2}{*}{10} & Terang & 11.4 & 0.017 & 1.425 & $1,600,000$ & \multirow{2}{*}{$10,720,000$} \\
\hline & Gelap & 42.2 & 0.063 & 5.275 & $1,600,000$ & \\
\hline \multirow{2}{*}{11} & Terang & 7.8 & 0.012 & 0.975 & $1,600,000$ & \multirow{2}{*}{$9,400,000$} \\
\hline & Gelap & 39.2 & 0.058 & 4.900 & $1,600,000$ & \\
\hline \multirow{2}{*}{12} & Terang & 4.9 & 0.007 & 0.613 & $1,600,000$ & \multirow{2}{*}{$6,260,000$} \\
\hline & Gelap & 26.4 & 0.039 & 3.300 & $1,600,000$ & \\
\hline
\end{tabular}

Sumber: data olahan primer 2016 
Total penerimaan penangkapan benih sidat selama satu tahun sebesar Rp.59.000.000 per tahun. Total tersebut belum dikurangi biaya oprasional penangkapan sebesar Rp.21.380.000 per tahun. Produktifitas alat tangkap merupakan hasil tangkapan per trip atau per nelayan dari tabel 4. rata-rata hasil tangkapan per nelayan yang paling tinggi sebesar $5.275 \mathrm{Kg} /$ periode bulan dan penangkapan tersebut dilakukan ketika fase gelap bulan, sedangkan yang paling rendah sebesar $0.225 \mathrm{Kg} /$ periode bulan dan penangkapan tersebut dilakukan ketika fase terang bulan.

Produktifitas yang rendah umumnya disebabkan oleh rendahnya keterampilan dan pengetahuan serta penggunaan alat penangkapan maupun perahu yang masih sederhana, Barus $H$. R, Badrudin, N, Naamin. (1991). Hasil tangkapan tersebut menunjukan waktu yang tepat dalam melakukan penangkapan benih sidat dilakukan saat fase gelap bulan, hal ini termasuk dalam sifat alami benih sidat yang menghindari predator dimana mereka akan merasa aman beruaya disaat kondisi gelap bulan.

\section{Kriteria ekonomi penangkapan benih sidat}

Kriteria dalam menganalisis ekonomi usaha penangkapan jaring rampus antara lain Keuntungan bersih, revenue cost ratio $(R / C$ ratio), return of investment $(\mathrm{ROI})$, dan payback period $(P P)$.

\section{A. Keuntungan bersih}

Analisis laba/rugi bertujuan untuk mengetahui besarnya keuntungan atau kerugian dari usaha yang dikelola (Effendi dan Oktariza, 2006). Keuntungan merupakan hasil pengurangan dari pendapatan total dengan biaya total. Apabila suatu usaha nilai total pendapatan lebih besar dari biaya total maka usaha tersebut menguntungkan, apabila total pendapatan lebih rendah dari total biaya maka usaha tersebut mengalami kerugian.berdasarkan hasil penelitian, jumlah keuntungan pada usaha penangkapan benih sidat yaitu Rp. 37.620.000 per tahun.

\section{B. Revenue cost ratio ( $R / C$ ratio)}

Penerimaan yang diperoleh dari usaha penangkapan benih sidat adalah sebesar Rp. 59.000.000 per tahun. Total biaya yang dikeluarkan adalah Rp. 21.380.000 per tahun, diperoleh nilai $R / C$ ratio sebesar 2.75. Analisis $\mathrm{R} / \mathrm{C}$ merupakan alat analisis untuk melihat keuntungan relatif suatu usaha dalam satu tahun terhadap biaya yang dipakai dalam kegiatan tersebut. Suatu usaha dikatakan layak bila R/C lebih besar dari 1 (R/C>1) (Effendi dan Oktariza, 2006). Usaha penangkapan benih sidat memiliki nilai R/C 2.75 yang berarti usaha ini layak untuk dilakukan.

\section{Return of investment (ROI)}

Return of investment (ROI) digunakan untuk mengetahui tingkat keuntungan dari biaya yang dikeluarkan untuk biaya investasi usaha, maka diperoleh sebesar 75.24\%, artinya tingkat keuntungan yang diperoleh dari 1 rupiah yang ditanamkan adalah sebesar 7524 rupiah atau besarnya kemampuan untuk pengembalian modal investasi usaha penangkapan benih sidat mencapai $75.24 \%$ dengan asumsi pendapatan pada setiap bulan dan tahunnya tetap.

\section{Payback period (PP)}

Penghitungan payback period ( $P P)$ digunakan untuk mengetahui berapa lama waktu yang diperlukan untuk menutupi modal investasi yang dikeluarkan dalam hitungan tahun atau bulan (Effendi dan Oktariza, 2006).diperoleh sebesar 0,16, artinya waktu yang diperlukan untuk pengembalian modal investasi yang dikeluarkan adalah selama 0,16 tahun atau sama dengan 1 bulan 28 hari

Menurut Effendi dan Oktariza (2006), usaha perikanan yang akan dilakukan oleh seorang pengusaha harus menghsailkan keuntungan yang berkelanjutan. Oleh karena itu perlu dilakukan analisis usaha. Analisis usaha merupakan salah satu cara untuk mengetahui tingkat kelayakan dari suatu usaha dengan tujuan mengetahui tingkat keuntungan, pengembalian investasi, dan waktu yang dibutuhkan untuk pengembalian modal. Analisis usaha pada suatu usaha perikanan sangat di perlukan mengingat ketidak pastian usaha yang cukup besar, apalagi usaha perikanan tangkap dan pengolahan hasil perikanan yang 
sangat dipengaruhi oleh musim penangkapan. Hasil analisis peanangkapan benih sidat menggunakan alat tangkap seser dimuara Cibuni Tegal Buleud seperti yang terdapat pada Tabel 5.

Tabel 5. Analisis Usaha Penangkapan Benih Sidat

\begin{tabular}{llll} 
No & \multicolumn{1}{c}{ Analisi Usaha } & \multicolumn{1}{c}{$\begin{array}{c}\text { Biaya Hasil } \\
\text { Analisis }\end{array}$} & Keterangan \\
\hline 1 & Keuntungan & 37.620 .000 & Rupiah $(\mathrm{Rp})$ \\
2 & Revenue cost ratio $($ R/C ratio $)$ & 2.75 & Layak \\
3 & Return of investment $(\mathrm{ROI})$ & 75.24 & persen \\
4 & Payback period $(P P)$ & 0.16 & tahun \\
\hline
\end{tabular}

\section{Waktu yang Efektif dalam Usaha Penangkapan Benih Sidat}

Penentuan waktu yang efektif dalam penangkapan benih sidat di muara Cibeni Tegal Buleud, Sukabumi, Jawa Barat dilakukan dengan menggunakan analisis deskriptif kuantitatif. Analisis deskriptif kuantitatif menggunakan metode uji anova di mana diasumsikan bahwa data telah tersebar normal dan untuk menentukan nilai Ftab dan Fhit mengunakan aplikasi SPSS. Berikut adalah tabel 6. hasil uji anova.

Tabel 6. Hasil uji anova

\begin{tabular}{lcrcccc}
\hline Source of Variation & \multicolumn{1}{c}{ Jkt } & \multicolumn{1}{c}{ Df } & Kt & fhit & P-value & ftab \\
\hline Between Groups & 880.8817 & 1 & 880.8817 & 10.78637 & 0.003386106 & 4.30095 \\
Within Groups & 1796.657 & 22 & 81.66621 & & & \\
Total & 2677.538 & 23 & & & & \\
\hline
\end{tabular}

Sumber: Analisis data primer 2016

Dapat dilihat pada tabel. F hitung sebesar 10.78637 dan F tabel sebesar 4.30095 karena Fhitung lebih besar dari pada Ftabel maka Tolak H0. Dengan demikian di Muara Sungai Cibuni Tegal Buleud periode fase bulan berpengaruh nyata terhadap produksi glass eel. Sehingga waktu yang efektif dalam penangkapan benih sidat adalah saat waktu gelap bulan dikarenakanan ikan sidat tidak bermigrasi selama terang bulan ini adalah tingkah laku ikan sidat untuk menghindari predator dan ada hubungannya dengan intensitas cahaya (Sriati 1998).

\section{KESIMPULAN}

Berdasarkan pengoprasiannya alat tangkap seser yang digunakan nelayan muara Cibuni Tegal Buleud, Sukabumi, Jawa barat dapat diklasifikasikan sebagai alat tangkap lift net. Usaha penangkapan benih sidat menggunakan alat tangkap seser layak untuk dilakukan atau masih menguntungkan. Waktu yang efektif dalam penangkapan benih sidat yaitu saat kondisi gelap bulan.

\section{DAFTAR PUSTAKA}

Affandi R dan Suhenda N. 2003. Teknik Budidaya Ikan Sidat (Anguilla bicolor bicolor.). Di dalam: Setiawan IE, Sudaryanto A, Riyadi AS, editor. Prosiding Forum Nasional Sumberdaya Perikanan Sidat Tropik; UPT Baruna Jaya - BPPT, Maret 2003. Jakarta.

Affandi R. 2005. Strategi Pemanfaatan Sumberdaya Ikan Sidat, Anguilla spp. di Indonesia. Jurnal Iktiologi Indonesia, Volume 5, No. 2: 77-81

Aoyama j. 2009. Life History and Evolution of Migration in Catadromous Eels (Anguilla sp.). Aqua- 
Bio Science Monograph (AMSM), Vol 2, no. 1, pp 1-42

Amerind Publishing Co. Pct. Ltd. New Delhi, Bombay, Calcuta, New York. 133p.

Barus H. R, Badrudin, N, Naamin., 1991. Potensi Sumberdaya Perikanan Laut dan Strategi Pemanfaatannya Bagi PengembanganPerikanan yang Berkelanjutan.

CITES. 2007. CoP14 Prop. 18. Consideration of Proposals for Amendment of Appendices I and II Inclusion of Anguilla anguilla (L.) in Appendix II in accordance with ArticleII §2(a). 37 hal. http://www.cites.org/eng/cop/14/prop/E14-P18. pdf (Download 12 Maret 2016).

Effendi, I. dan Oktariza, W. 2006. Manajemen Agribisnis Perikanan. Penebar Swadaya. Jakarta.

Fahmi MR dan Himarwati R. 2010. Keragaman Ikan Sidat Tropis (Anguilla sp.) di Perairan Sungai Cimandiri, Pelabuhan Ratu, Sukabumi. Di dalam: Fahmi MR, editor. Prosiding Forum Inovasi Teknologi Akuakultur; Balai Riset Budidaya Ikan Hias, Desember 2010. Depok.

Irawan A. 2008. Makalah Tingkah Laku Ikan Sidat (Anguilla sp.) Respon Terhadap Lingkungan dan Naluri Berpijah. Purwokerto: Universitas Jendral Soedirman.

Iskandar. 2001 . Lenis Alat Tangkap Jaring Angkat (lift nets). Malang.254 Hal.

Kementerian Kelautan dan Perikanan RI. 2009. Peraturan Menteri Kelautan dan Perikanan Republik Indonesia Nomor Per. 18/Men/2009 Tentang Larangan Pengeluaran Benih Sidat (Anguilla spp.) dari Wilayah Negara Republik Indonesia ke Luar Wilayah Negara Republik Indonesia. 4 hal.

Kottelat M, Whitten AJ, Kartikasari SN, Wirjoatmodjo S. 1993. Freshwater Fishes of Western Indonesia and Sulawesi. Edisi dwi bahasa Inggris - Indonesia, Periplus ed. 293 p.

Lagler K F, Bardach J E, Miller R R. and Passino D R M. 1977. Ichthyolgy. John Willey \& Sons. New York. 506p.

Lucas MC and Baras E. 2001. Migration of Freshwater Fishes. Blackwell Science. London, 440 pp.

Matsui I. 1970. Theory and Practice of Eel Culture (Aquaculture Serie 4).

McDowall R M. 1997. The Evolution of Diadromy in Fishes (revisited) and Its Place in Phylogenic Analysis. Fish Biology and Fisheries. 7:443-462.

Sarwono B, 2007. Budidaya Belut dan Sidat. Edisi Revisi. Penerbit Penebar Swadaya. Jakarta. 87 hal.

Sasongko A, Purwanto J, Mu'minah S, Arie U. 2007. Sidat Panduan Agribisnis Penangkapan, Pendederan, dan Pembesaran. Jakarta: Penebar Swadaya.

Subani W dan Barus H R. 1989. Alat Penangkapan Ikan dan Udang Indonesia. Nomor 59 Tahun 1988/199. Edisi Khusus. Jurnal Penelitian Perikanan Laut. Jakarta: Balai Penelitian Perikanan Laut, Badan Penelitian Perikanan Laut, Departemen Pertanian.

Tabeta O. 1976. Seasonal occurrence of Anguillid elvers in Cagayan river, Luzon Island. Philipines: Bull Japan Social Science Fish. 42(4) : $421-426$. 